\title{
The Annals of Applied Probability
}

\section{Vol. 1}

August 1991

No. 3

Special Invited Paper

Loss networks

F. P. KeLLY

\section{Articles}

Diffusion approximation in past dependent models and applications to option pricing

Paolo Kind, Robert Sh. Liptser and Wolfgang J. Runggaldier

On the distribution of leaves in rooted subtrees of recursive trees

Hosam M. Mahmoud and R. T. Smythe

Inventory models with continuous, stochastic demands . S SIDNEY Browne AND PAUL ZIPKIN

A limit result respecting graph structure for a fully connected loss network with

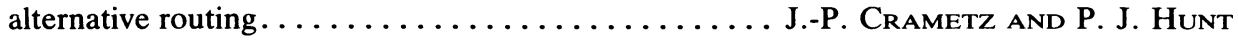

Pseudolikelihood for exponential family models of spatial point processes

Jens Ledet Jensen and Jesper Møller

A new class of random number generators........ George MARSAGLia ANd ARIf Zaman

Vol. 1

November 1991

No. 4

\section{Articles}

A mean field limit for a lattice caricature of dynamic routing in circuit switched

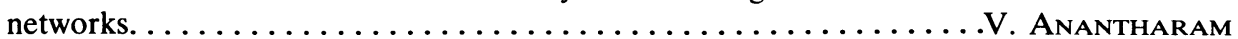

Estimating variance from high, low and closing prices

L. C. G. Rogers and S. E. SAtchell

Some limit theorems on distributional patterns of balls in urns

Samuel Karlin and Ming-Ying Leung

On the functional central limit theorem for the Ewens sampling formula

Peter Donnelly, Thomas G. Kurtz and Simon Tavaré

Departures from many queues in series ............ Peter W. Glynn And Ward Whitt

A branching random walk with a barrier

J. D. Biggins, Boris D. Lubachevsky, Adam Shwartz and Alan Weiss Nonlinear regression of stable random variables

Clyde D. Hardin, Jr., Gennady Samorodnitsky and Murad S. Taqqu On the ergodicity of TAR(1) processes............RONG CHEN AND RuEY S. TsAy

All correspondence and submissions for the Annals of Applied Probability should be directed to:

\author{
J. Michael Steel, Editor \\ The Wharton School \\ The University of Pennsylvania \\ Department of Statistics \\ 3010 Steinberg Hall-Dietrich Hall \\ Philadelphia, Pennsylvania 19104-6302, USA \\ (215) 898-9477 \\ E-mail: steele@wharton.upenn.edu
}

Papers should be submitted in quadruplicate, and authors are encouraged to follow the familiar editorial conventions of the two other IMS Annals. In addition to welcoming papers in all the traditional areas of applied probability, the new Annals particularly hopes to attract work that develops and deepens the interplay of probability and the fields of computer science, finance, network modeling, and biology. 


\section{THE MATHEMATICAL SCIENTIST (TMS)}

This publication contains papers on a variety of mathematical topics for the general information and enjoyment of mathematicians, statisticians and computer scientists; it also appeals to workers in any other discipline lending itself to the application of mathematical methods. Readers are encouraged to submit short papers, letters and problems concerned with the theory and application of mathematics, statistics or computing. Material for publication should be presented in a clear and simple style, suitable for an informed but non-specialist mathematical audience, and may be sent to any member of the editorial board:

Editor-in-chief: J. Gani (Australian National University, Canberra)

Editors:

R. Anderssen (CSIRO, Canberra), Rosemary Bailey (Goldsmiths' College, London), J. Blake (University of Birmingham), Paul M. Cohn (University College London), W. Forbes (University of Waterloo), John Gower (Rothamsted Experimental Station, Harpenden), C. C. Heyde (Australian National University, Canberra), K.-H. Hoffmann (Universität Augsburg), A. Konheim (University of California, Santa Barbara), Hilary Ockendon (Mathematical Institute, Oxford), Basil Rennie (Burnside, S. Australia), S. Resnick (Cornell University, Ithaca, NY), G.-C. Rota (Massachusetts Institute of Technology), and R. Stanton (University of Manitoba, Winnipeg).

Each volume consists of two issues distributed in June and December, totalling approximately 128 pages. Volume 16 (1991) costs $£ 8.00$ (US\$13.50, \$A. 17.50).

It includes the following contributions:

The mathematics of darts (or where to aim), by C. Atkinson and R. Craster

Embedding procedures for discrete problems in probability, by G. Blom and L. Holst

On harmonic means and variances, by E. A. Catchpole and A. W. Plank

Simulations of enhanced oil recovery, by M. K. Cham and J. R. Blake

Lagrange interpolation polynomials based on equidistant nodes, by T. M. Mills and S. J. Smith

Problems of handling messy field data for engineering decision-making, by E. Moore, J. J. Sharp and L. M. Lye

Double Youden rectangles of size $6 \times 11$, by D. A. Preece

Point processes and Tauberian theory, by S. Resnick

A generalized birthday problem, by $\mathrm{D}$. Sandell

Renewal process proof for the limit of the Markov binomial distribution, by Y. H. Wang and W. J. Bühler

Stochastic modelling of dose-response for single cells in radiation experiments, by G. L. Yang and C. E. Swenberg

Orders and requests for further information should be sent to

Executive Editor, Applied Probability,

Department of Probability and Statistics,

The University, Sheffield S3 7RH,

England. 


\section{SUBSCRIPTION RATES}

Subscription rates (post free) for the 1991 volume of Advances are as follows:

Subscribers in North, Central and South America, and Australia:

US $\$ 150.00 ; \$ A 198.00 ; £ 87.00$ for libraries and institutions;

US\$50.00; $\$ A 66.00 ; £ 29.00$ for individuals belonging to a recognised scientific society.

\section{All other subscribers:}

$£ 87.00$ for libraries and institutions;

$£ 29.00$ for individuals belonging to a recognised scientific society.

All enquiries about Advances, as well as other subscriptions, should be sent to the Executive Editor, Miss M. Hitchcock, Department of Probability and Statistics, The University, Sheffield S3 7RH, England. The price of back numbers varies from volume to volume, and enquiries should be sent to the Executive Editor. Cheques, money orders, etc. should be made out to Applied Probability; cheques on U.S., U.K. and Australian banks will be acceptable.

\section{NOTES FOR CONTRIBUTORS}

Contributions published in Advances may be of six kinds:

(1) review papers; (2) longer research papers in applied probability, which may include expository material; (3) expository papers on branches of mathematics of interest to probabilists; (4) papers outlining areas in the biological, physical, social and technological sciences in which probability models can usefully be developed; (5) papers in applied probability presented at conferences which do not publish their proceedings; (6) letters to the editor on any appropriate topic in applied probability. (Note: Letters relating specifically to papers which have appeared in the Journal of Applied Probability will continue to be published in the Journal.)

Research papers not exceeding 20 printed pages and short communications are published in the Journal of Applied Probability. The editors may publish accepted papers in either journal, according to the space available, in order to meet the 15-month deadline in publication referred to below.

\section{Submission of papers}

Papers submitted to Advances in Applied Probability are considered on the understanding that they have not been published previously and are not under consideration by another publication. Papers will not be reprinted without the written permission of the Trust. It is the policy of Advances not to accept for publication papers which cannot appear in print within 15 months of the date of receipt of the final version. Authors will receive 50 reprints of their papers free, and joint authors a proportional share of this number. Additional reprints will be provided at cost.

Papers should be written in English or French; papers in other languages may be accepted by the editors, but will appear (subject to the author's agreement) in English or French translation in Advances. Scripts should be typewritten, using double spacing, and at least one copy should be on one side of the paper only. Each paper should be accompanied by

(i) a short abstract of approximately 4-10 lines giving a non-mathematical description of the subject matter and results;

(ii) a list of keywords detailing the contents for the purpose of computerised information retrieval;

(iii) primary and secondary classifications using the 1991 Mathematics Subject Classification, to be found in the 1990 Annual Index of Mathematical Reviews.

Authors are advised to consult The Author's Guide to the Applied Probability Journals when preparing papers for submission. A copy of this guide may be obtained on application to the Applied Probability Office.

For efficiency in processing, authors are requested to send three copies of all submissions to the Applied Probability Office in Sheffield, rather than to individual editors. Authors overseas are asked to ensure that their submissions are sent by airmail. The Editor-in-Chief and the Applied Probability Office are in regular contact and full details of all papers submitted are available to Professor Heyde at The Australian National University in Canberra.

\section{Copyright}

The copyright of all published papers shall be vested in the Trust. When a paper is accepted for publication, the Trust requests the author(s) to sign a form assigning copyright to the Trust. Failure to do this promptly may delay or prevent publication.

Authorisation to photocopy items for internal or personal use, or the internal or personal use of specific clients, is granted by the Applied Probability Trust for libraries and other users registered with the Copyright Clearance Center (CCC) Transactional Reporting Service, provided that the base fee of $\$ 00.50$ per copy, plus .10 per page is paid directly to CCC 27 Congress St., Salem, MA 01970, U.S.A. $0001-8678 / 91 \$ 00.50+.10$. 
667 J. M. McNAMARA, S. MERAD AND E. J. COLLINS. The HawkDove game as an average-cost problem

683 ERIK A. VAN DOORN. Quasi-stationary distributions and convergence to quasi-stationarity of birth-death processes

701 D. A. DAWSON AND K. J. HOCHBERG. A multilevel branching model

716 B. CHAUVIN, P. OLIVARES-RIEUMONT AND A. ROUAULT. Fluctuations of spatial branching processes with mean-field interaction

733 LAJOS HORVÁTH. Weak convergence of discrete scattering processes

751 CLIVE R. LOADER. Large-deviation approximations to the distribution of scan statistics

772 FRANK BALL, ROBIN K. MILNE AND GEOFFREY F. YEO. Aggregated semi-Markov processes incorporating time interval omission

798 GYÖRGY TERDIK AND LAURIE MEAUX. The exact bispectra for bilinear realizable processes with Hermite degree 2

809 P. WHITTLE. A stochastic model of an artificial neuron

823 DIETMAR PFEIFER. Some remarks on Nevzorov's record model

835 MICHAEL R. CHERNICK, TAILEN HSING AND WILLIAM P. McCORMICK. Calculating the extremal index for a class of stationary sequences

851 ANANT P. GODBOLE. Poisson approximations for runs and patterns of rare events

866 HEIKKI HAARIO AND EERO SAKSMAN. Simulated annealing process in general state space

894 M. T. CHAO AND JAMES C. FU. The reliability of a large series system under Markov structure

909 RHONDA RIGHTER AND SUSAN H. XU. Scheduling jobs on non-identical IFR processors to minimize general cost functions

925 CHENG-SHANG CHANG, RANDOLPH NELSON AND MICHAEL PINEDO. Scheduling two classes of exponential jobs on parallel processors: structural results and worst-case analysis

945 WIM M. NAWIJN. On a random interval graph and the maximum throughput rate in the system $G I / G / 1 / 0$

957 WEN-JANG HUANG AND PREM S. PURI. A queueing process with the possibility of customers becoming servers

Letters to the editor

972 GUILLERMO AYALA, JUAN FERRANDIZ AND FRANCISCO MONTES. Random set and coverage measure

975 YOU-GAN WANG AND JOHN GITTINS. A note on Gittins indices for pharmaceutical research

978 Index

Published by the Applied Probability Trust

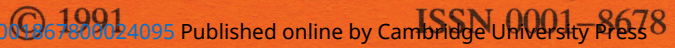

